\title{
Early Age Concrete Strength Monitoring Using Power Spectral Density and Wavelet Packet Analysis
}

\author{
Xia Yang $\mathbb{D},^{1,2}$ Wenwei Yang $\mathbb{D D}^{1,2}$ Shuntao $\mathrm{Li}^{3}$ and Chang $\mathrm{Wu}^{2,4}$ \\ ${ }^{1}$ School of Civil and Hydraulic Engineering, Ningxia University, Yinchuan 750021, China \\ ${ }^{2}$ Ningxia Center for Research on Earthquake Protection and Disaster Mitigation in Civil Engineering, Yinchuan 750021, China \\ ${ }^{3}$ College of Civil Engineering, Hunan University, Changsha 410082, China \\ ${ }^{4}$ School of Civil Engineering, Lanzhou University of Technology, Lanzhou 730050, China
}

Correspondence should be addressed to Xia Yang; jggcyangxia@163.com and Wenwei Yang; yww@nxu.edu.cn

Received 29 August 2020; Revised 7 November 2020; Accepted 15 November 2020; Published 27 November 2020

Academic Editor: Giuseppe Quaranta

Copyright ( $\odot 2020$ Xia Yang et al. This is an open access article distributed under the Creative Commons Attribution License, which permits unrestricted use, distribution, and reproduction in any medium, provided the original work is properly cited.

\begin{abstract}
Concrete is a complex building material. Under normal curing conditions, concrete strength shows a nonlinear development process at an early age (1 $28 \mathrm{~d})$. In the first few days after the completion of pouring, the strength of concrete increases slowly. Subsequently, the strength of concrete increases rapidly, reaching about $90 \%$ of its age strength. Finally, its strength gradually stabilizes. This paper introduces the experiment of 28-day concrete age strength monitoring based on embedded piezoelectric smart aggregate (SA). Two piezoelectric SAs were embedded in a concrete-filled GFRP (glass fiber reinforced polymer) tube column, one of which emitted a sinusoidal sweep signal and the other SA received the signal. With the hydration reaction of concrete, the stress wave would be significantly different when passing through concrete, and the received signal is changing constantly. Through power spectral density and wavelet packet energy analysis, the monitoring signal of concrete age within 28 days was analyzed. The experimental results show that the wavelet packet energy and power spectral density of the sensor monitoring signal show a nonlinear growth trend with time during the concrete target age. It can be divided into three stages, and the fifth day and the fourteenth day are the demarcation point of energy growth. And the trend of energy change corresponds well with the change of actual concrete strength and age. Comparing and analyzing the received signal energy of the sensor and the power spectral density function of the stress wave signal of the concrete specimen, the trend of the amplitude in the natural frequency domain is found to be the same in the three stages.
\end{abstract}

\section{Introduction}

Concrete is one of the most widely used building materials in modern buildings due to its relatively low material cost, high durability, and versatility, and its material strength is directly related to the safety of buildings. Concrete is a heterogeneous material with a complex microstructure, mainly composed of water, cement, sand, stones, and other additives. It is often mixed on site. In terms of strength and durability, the quality of the final product highly depends on the process of mixing, handling, installation, vibrating, and curing. And the final performance of concrete also depends on its treatment after reaching the construction site [1]. Therefore, strengthening the early strength monitoring of concrete to ensure the efficiency and effectiveness of consolidation and curing procedures are critical for attaining the full potential of a concrete mixture.

At present, the conventionally used methods for detecting the strength of concrete mainly include the rebound method, ultrasonic-rebound method, core drilling method, pulling-out method, postanchoring method, and decompression method [2-4]. Although these methods are simple and reliable, they often cause some damage to the structure.

In recent years, the emergence of smart materials provides an effective way for structural health monitoring. Structural health monitoring technology based on piezoelectric materials has developed rapidly and attracted 
extensive attention of many scholars. In particular, the use of piezoelectric materials to study the age strength of concrete has proved to be an effective way [5-7]. Electromechanical impedance (EMI) is a method for detecting structural characteristics and state changes of piezoelectric materials based on smart impedance analysis [8-11]. Professor Soh's research group [12-14] analyzed and proposed an empirical method for determining the strength of concrete on site based on the change of admittance signal of surface-bonded PZT (lead zirconate titanate) sensor. Subsequently, research on the prediction of concrete strength development based on EMI method has attracted many scholars' interest. The results show that the EMI method is very sensitive to the early development of concrete strength, so it is considered suitable for the monitoring of concrete strength development. The research from professor Inman [15-17] focuses on the monitoring of structural mechanical properties of PZT sensors. The research team of Zhu [11, 18-20] used PZT sensors to conduct a series of experimental studies on bolt loosening of steel frame structures, solidification process of concrete cubes, and temperature compensation of piezoelectric impedance technology, which promoted the application of EMI method in civil engineering.

In addition, active sensing based on wave propagation theory is also widely used in structural health monitoring to detect cracks and other damage in the structure [21-30]. Song et al. [31, 32] first proposed the concept of piezoelectric smart aggregate (SA), which is to pack the piezoelectric ceramic piece with marble to achieve its protection. Two SAs are embedded in concrete. One SA transmits signals and the other SA receives signals. Zhu et al. [33] utilized piezoceramic bender elements and successfully measured the velocities of the P-wave and S-wave during the first $6 \mathrm{~h}$ of very early age concrete paste hydration. Kong et al. [34] used the swept sine wave and the constant frequency sine wave excitation methods to monitor the signals received by the sensors during the hydration of the early age $(0-20 \mathrm{~h})$ of the concrete. Through the amplitude level and frequency domain analysis, three states during the concrete hydration were found: (1) the liquid state, (2) the transition state, and (3) the hardened state. Chung et al. [35] tested the strength of early age concrete and mortar slab specimens based on the piezoelectric active sensing method. Chen et al. [36] designed a wireless sensor network based on piezoelectric SA, which can realize early concrete strength monitoring. Based on piezoelectric impedance technology, Cai et al. [37] carried out the monitoring test of concrete strength development and established the quantitative relationship between the conductivity spectrum and the compressive strength of the standard test block.

However, the concrete hydration performance at an early age (1-28 days) has not received enough attention in most of the research. It is well known that the strength at the age of 28 days of concrete is a very significant parameter in engineering practice, and it is called standard strength. The early age concrete hydration is a very important part of the entire concrete hydration and the concrete experiences a complicated chemical reaction from the liquid stage to the hardened stage during the first 28 days after concrete casting.
Gu et al. [38] employed an SAs-based active sensing method to monitor strength development during concrete hydration from day 1 to day 28 by sending single frequency harmonics and proposed a fuzzy logic system based on the received signal amplitude to evaluate it, but there are still several problems in their experiment: (1) they used the first generation SAs with cement mortar as the protective shell, in which the performance of the embedded PZT sheet will be seriously affected by cement hydration, and it would make a difference in the experimental results; (2) they used single frequency harmonics to monitor, which are easily distorted by external interference; (3) they only chose the signal amplitude that is easily influenced by the external environment to judge the concrete age strength, which lacks persuasion; (4) their work was published 15 years ago when the technology for monitoring piezoelectric signals was not yet fully developed. Based on the above considerations, the experimental research of early age concrete strength monitoring using power spectral density and wavelet packet analysis begins.

Glass fiber reinforced polymer (GFRP) is a kind of composite material which is made of resin and glass fiber, with resin as a matrix and glass fiber as a reinforcing material $[39,40]$. It has the advantages of high tensile strength, good corrosion resistance, lightweight, good elastic deformation, thermal expansion coefficient close to concrete. In recent years, as a new kind of composite structures, the use of GFRP tube confined concrete columns have received increasing interest in engineering [41, 42].

In this paper, two SAs are embedded in concrete-filled GFRP tube column by the active sensing method. One SA emits a swept sine signal and the other SA receives a signal. During the early age of concrete, the hydration reaction will change the internal properties of concrete structure, which causes the stress waves to change as they pass through the concrete and the acquired signals behave differently. From the perspective of energy and power analysis, this paper describes the combination of wavelet packet energy and power spectral density analysis in concrete age strength monitoring. Through the comparative analysis of the strength development of the whole hydration process of concrete, the early strength growth period of the three stages of concrete was found. This shows that the analysis method combining wavelet packet energy and power spectral density analysis is accurate and efficient. The result shows that it is a signal analysis method with high application value and can provide a basis for determining the strength of concrete age in engineering practice.

\section{Test Method and Theory}

2.1. Test Method. Lead zirconate titanate (PZT), as one of the most widely used intelligent materials at present, can generate an electric charge when subjected to a stress or strain and can likewise generate a stress or a strain when subjected to an electric field. Due to its fast response, wide frequency response range, easy tailoring, and low price, it has great application potential in structural health monitoring [43-46]. In order to protect a fragile PZT patch, the first 
generation of SAs is made of a concrete block surrounding a waterproofed PZT patch and is successfully applied for several concrete structure health monitoring tests [34]. In this experiment, the second generation of SAs with the embedded piezoelectric patch was used, which was proposed by Kong and Song, and it consisted of a BNC wire, a piezoelectric patch, an epoxy resin protective layer, and a marble protective layer; it is illustrated in Figure 1. PZT patch is placed in the middle of the marble and bonded and encapsulated with epoxy resin for protection purposes. The size of the PZT patch is $15 \mathrm{~mm} \times 15 \mathrm{~mm}$, and the thickness is $0.3 \mathrm{~mm}$. The diameter of the SA is $25 \mathrm{~mm}$ and the height is $20 \mathrm{~mm}$, as shown in Figure 2. Parameters of the PZT patch used in the test are shown in Table 1.

The active sensing method was used in the experiment. The principle is that two piezoelectric sensors are embedded in the upper and lower ends of the concrete-filled GFRP tube column, as shown in Figure 3. One of the SA (actuator) is used as a driver to emit a fixed frequency band sweep sine signal under external electric field excitation. The stress wave signal propagates in the concrete medium, and finally another SA (sensor) converts the received stress wave signal into an electrical signal and outputs it. Because, in the course of curing, the change of concrete age strength largely depends on the process of concrete hydration, and the strength of concrete will gradually increase with the development of the hydration process, which is more conducive to the propagation of stress waves in concrete specimens. Under the same excitation signal, the energy of the received signal will increase accordingly. Therefore, the stress wave signals received can be theoretically analyzed in the time domain and frequency domain, and the change of the characteristic parameters of the received signals can be used to evaluate the growth process of concrete strength.

2.2. Signal Analysis Theory. There are many signal processing methods of structural health monitoring, among which wavelet packet and power spectral density analysis are commonly used processing methods [47]. Power spectral density analysis is an analysis method for obtaining pulsation information in time series [48-50]. It divides a finite sequence $x(n)\left(0 \leq n \leq N_{s}-1\right)$ into segments, each of which is $M$, and the overlap between segments is $M-K$. After adding the window function, the $i^{\text {th }}$ data segment can be represented as $x i=G(n) x(n+i K)(0 \leq i \leq L-1,0 \leq n \leq M-1), K$ is an integer, and $L$ is the number of segments. The relationship between them is satisfied $(L-1) K+M \leq N_{s}$, and $G(n)$ is a window function. The power spectral density of this data segment is estimated as

$$
P^{i}(\omega)=\frac{1}{\mathrm{MU}}\left|\sum_{n=0}^{M-1} X^{i}(n) e^{-j \omega n}\right|^{2},
$$

where $A$ is the normalization factor as

$$
U=(2 \pi M)^{-1} \int_{-\pi}^{\pi}|G(\omega)|^{2} \mathrm{~d} \omega
$$

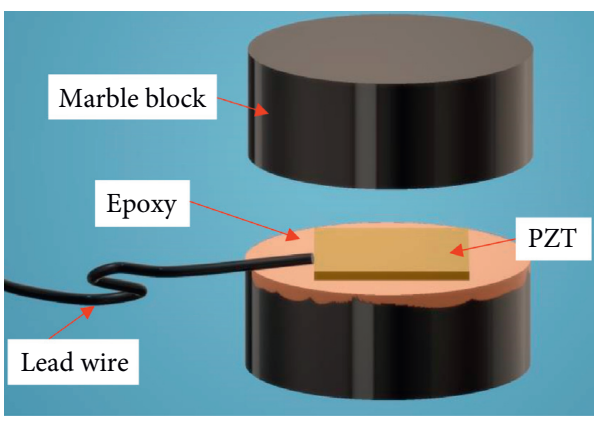

Figure 1: Structure of the SA.

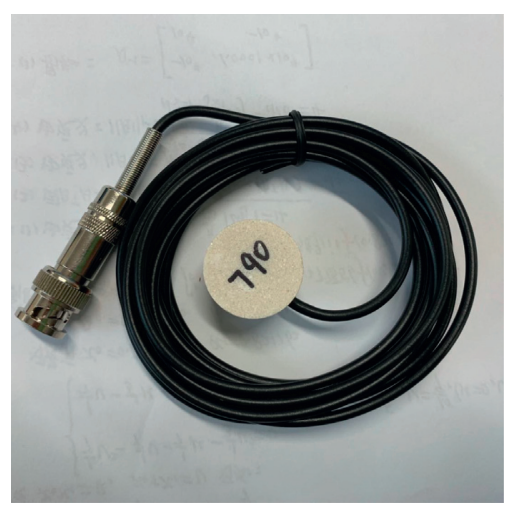

FIgURE 2: SA.

TABle 1: Parameters of the selected PZT patch.

\begin{tabular}{lc}
\hline Parameters & Value \\
\hline Young's modulus $(\mathrm{GPa})$ & 50 \\
Poisson ratio & 0.35 \\
Density $\left(\mathrm{kg} / \mathrm{m}^{3}\right)$ & 7.6 \\
Curie temperature $\left({ }^{\circ} \mathrm{C}\right)$ & 310 \\
Piezoelectric strain constant $(\mathrm{pC} / \mathrm{N})$ & 450 \\
Dielectric constant & 1800 \\
\hline
\end{tabular}

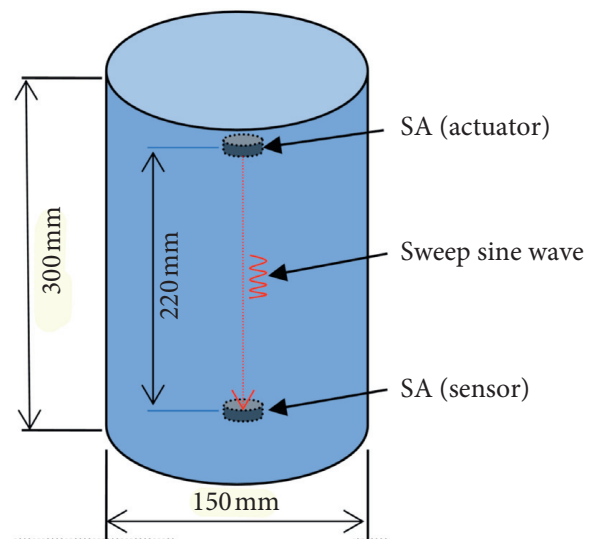

Figure 3: Experimental diagram.

The purpose of using normalization factor $U$ is to ensure that the obtained spectrum is an asymptotically unbiased estimation of the true power spectrum. The average power spectrum value obtained from this method is 


$$
\bar{P}(\omega)=\frac{1}{L} \sum_{i=0}^{L-1} P^{i}(\omega)=\frac{1}{\mathrm{LMU}} \sum_{i=0}^{L-1}\left|\sum_{n=0}^{M-1} X^{i}(n) e^{-j \omega n}\right|^{2} .
$$

Power spectral density analysis has good results in processing stationary and time-invariant signals.

Wavelet packet analysis is a more precise signal analysis method, and it is widely used in the signal postprocessing process of structural health monitoring based on piezoelectric transducer [51-55]. Assuming that the monitoring signal $S$ is analyzed by wavelet packet, $S$ can be decomposed into multiple signals with equal bandwidth. The monitoring signal of the sensor during concrete curing is decomposed by wavelet packet analysis. Wavelet packet analysis is used to decompose the monitoring signal of the sensor during concrete curing. $S$ is the original monitoring signal with $n$ sampling points. After $\mathrm{N}$-layer wavelet packet decomposition and reconstruction, $2 N$ subsignals $S_{i}\left(i=1,2, \ldots, 2^{N}\right)$ can be obtained as

$$
S_{i}=\left[S_{i, 1}, S_{i, 2}, \ldots, S_{i, j}, \ldots, S_{i, M-1}, S_{i, M}\right],
$$

where $i=1,2, \ldots, M$, where $M$ is the number of samples of the signal in the $i$-th band. After the signal is decomposed by the wavelet packet, the subband energy of each band in the last layer is $e_{i}=\sum_{j=1}^{M}\left|S_{i, j}\right|^{2}$. Then, the total energy of signal $S$ reconstructed by wavelet packet decomposition is as follows:

$$
E=\sum_{i=1}^{2 N} e_{i}
$$

\section{Experimental Setup}

As shown in Figure 4, the active detection system based on PZT transducers consists of the PC (Personal Computer) equipped with SCHYPZTV3 software, the multifunction piezoelectric signal detection and analysis system, two piezoelectric SAs, and a concrete-filled GFRP tube column with SAs embedded. The multifunction piezoelectric signal detection and analysis system is produced by Sanchuan Intelligent Technology Co., Ltd., from Jiangsu, China, and the model number is SC-HY-PZT-2.0. This active detection system integrates signal generator and oscilloscope, and realtime filtering can be performed in the process of data acquisition. In addition, this system can generate a variety of excitation signals, including sweep, pulse, and other arbitrary signals. In this paper, the authors mainly used sweep wave as excitation signals. Sweep signal is essentially a sine wave with continuously changing frequency, it can perform a linear dynamic frequency sweep for the structure. The characteristics of sweep excitation are simple and fast, and it can conveniently measure the frequency and dynamic characteristics of the system.

In this experiment, the height of the concrete-filled GFRP tube column is $300 \mathrm{~mm}$ and the diameter is $150 \mathrm{~mm}$. The grouting concrete label is C30. Two piezoelectric SAs were embedded in the specimen, and the distance between

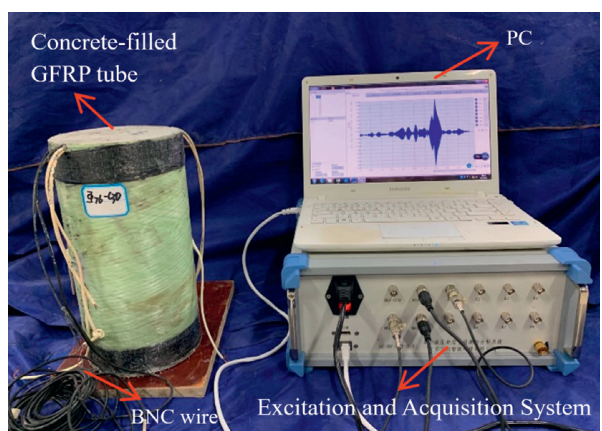

FIgURE 4: Composition of an active detection system based on piezoelectric transducers.

the piezoelectric actuator and piezoelectric sensor was $220 \mathrm{~mm}$; we can see this information from Figure 3. During the test, SA (actuator) transmits the signal as a driver and SA (sensor) receives the signal as a sensor. In order to remove the influence of noise, real-time filtering was performed in the whole process of the test. At the same time, to eliminate signal distortion caused by accidental errors, the data was not saved until the waveform was stable by multiple excitations.

The monitoring signal was selected as a swept sine wave. In the process of wave propagation, due to different materials having a different frequency response ranges to the signal [56], we need to carry out several pretests before the formal test to determine the frequency range of sweep signals. Firstly, a large range sweep frequency wave (such as $1 \mathrm{kHz}-500 \mathrm{kHz}$ ) was employed to excite the SA (actuator), and the time-domain waveform of the collected signal was observed, and it could be found the time period where the signal amplitude was larger, and then the approximate sweep range corresponding to this period could be calculated according to the sweep time. And then the calculated sweep range was used to excite. The above process was repeated to gradually reduce the sweep range until a suitable frequency range was finally determined. According to this method, the final sweep frequency range selected was $100 \mathrm{kHz}-200 \mathrm{kHz}$, the signal duration was $0.5 \mathrm{~s}$, the voltage was $10 \mathrm{~V}$, and the mode was linear sweep frequency. The advantage of swept sine waves as a monitoring signal is that the changing frequency can meet the changing requirements of concrete strength. The parameters of signal acquisition and filtering are given in Table 2. In this experiment, real-time data was recorded and saved every 24 hours until the concrete curing period reached 28 days.

\section{Experimental Results}

4.1. Frequency-Domain Responses of Received Signals. The received part of the original signal is shown in Figure 5. As can be seen from Figure 5, the signal shows a distinct peak around $0.35 \mathrm{~s}$. As the concrete age increases, the strength of the concrete increases with the hydration reaction, 
TABle 2: The parameters of signal acquisition and filtering.

\begin{tabular}{|c|c|c|c|c|c|}
\hline \multicolumn{2}{|c|}{ Incentive parameters } & \multicolumn{2}{|c|}{ Acquisition parameter } & \multicolumn{2}{|c|}{ Filtering parameter } \\
\hline Voltage & $10 \mathrm{~V}$ & Frequency & $1 \mathrm{MHz}$ & Filter & Butterworth \\
\hline Range & $100 \mathrm{kHz}-200 \mathrm{kHz}$ & Length & $512 \mathrm{k}$ & Type & Bandpass \\
\hline Frequency & $0.2 \mathrm{kHz}$ & Sampling time & $524 \mathrm{~ms}$ & Order & 5 \\
\hline Step size & $1 \mathrm{~ms}$ & Trigger mode & Normal & Range & $100 \mathrm{kHz}-200 \mathrm{kHz}$ \\
\hline
\end{tabular}

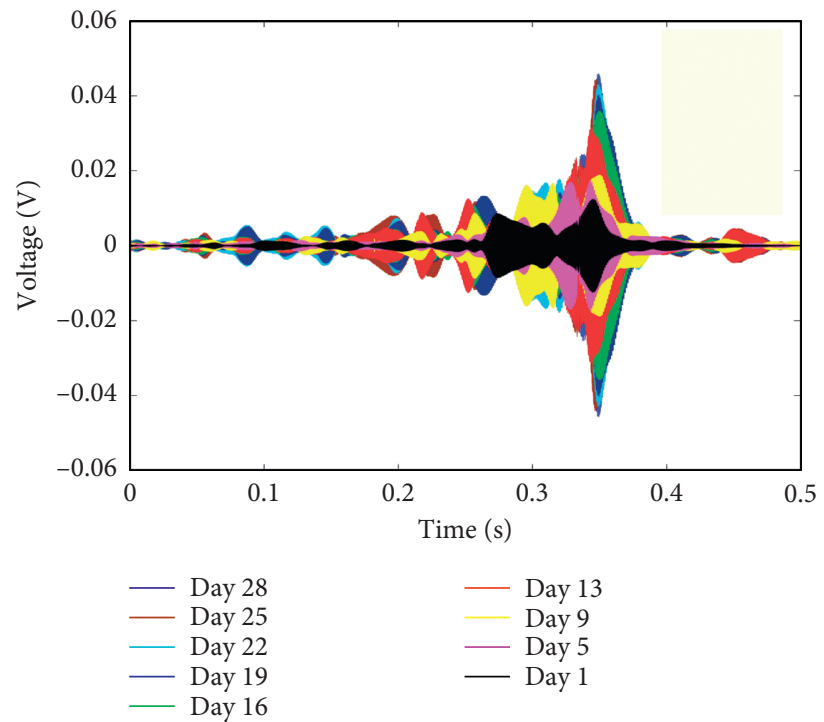

FIGURE 5: The received signal of the sensor.

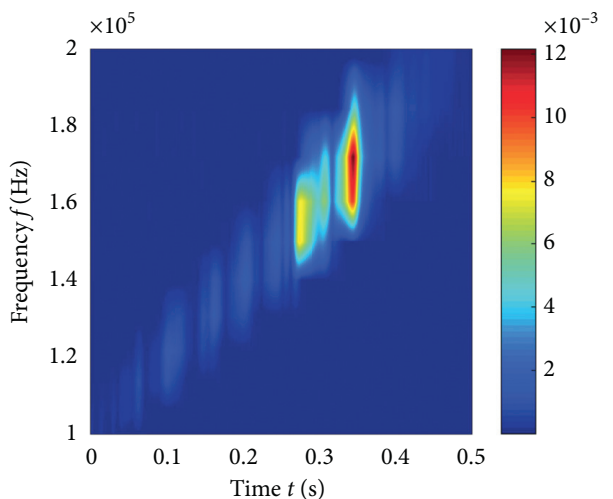

(a)

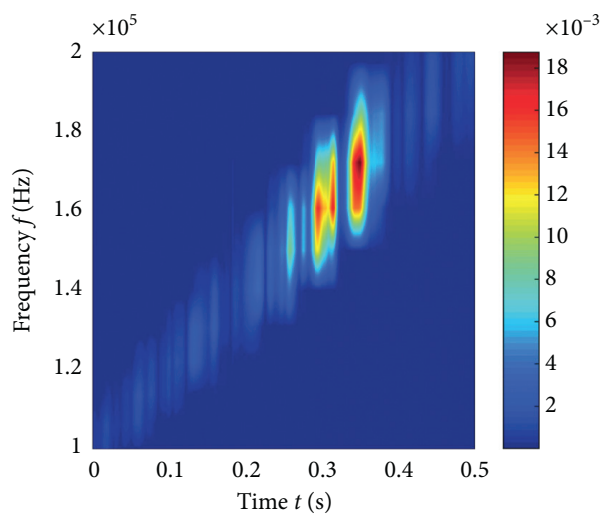

(c)

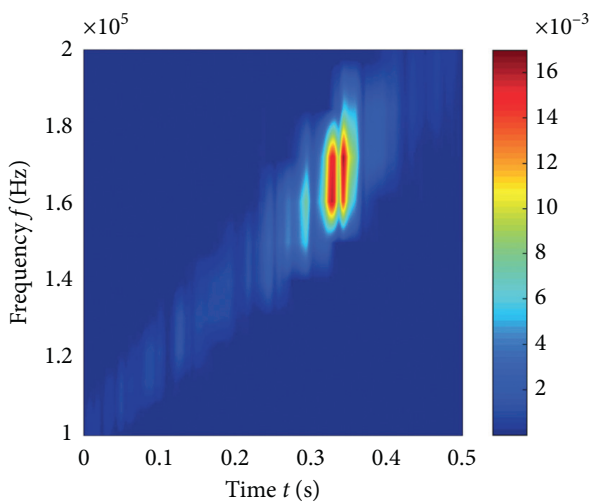

(b)

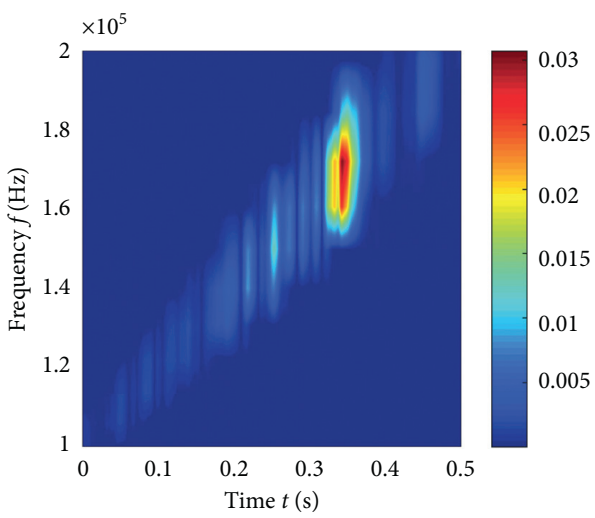

(d)

FIgUre 6: Continued. 


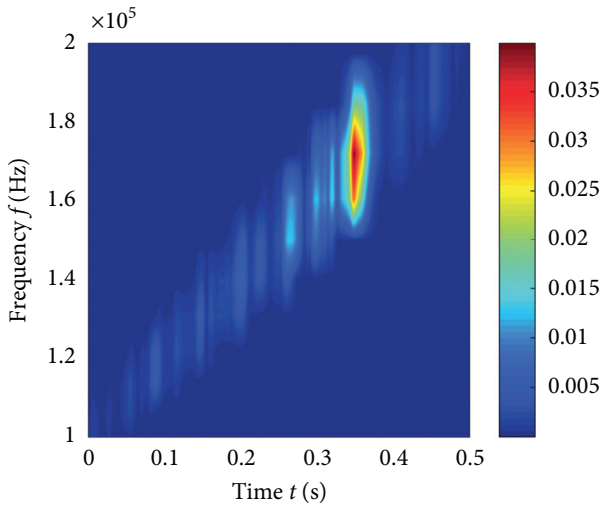

(e)

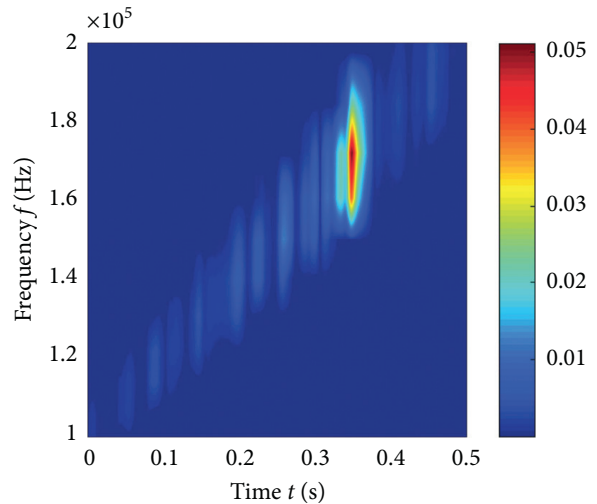

(f)

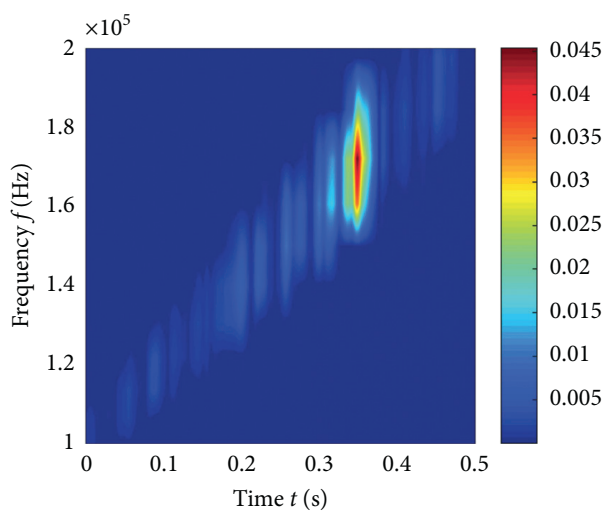

(g)

Figure 6: STFT time-frequency diagram, (a) day 1, (b) day 5, (c) day 9, (d) day 13, (e) day 19, (f) day 25, and (g) day 28.

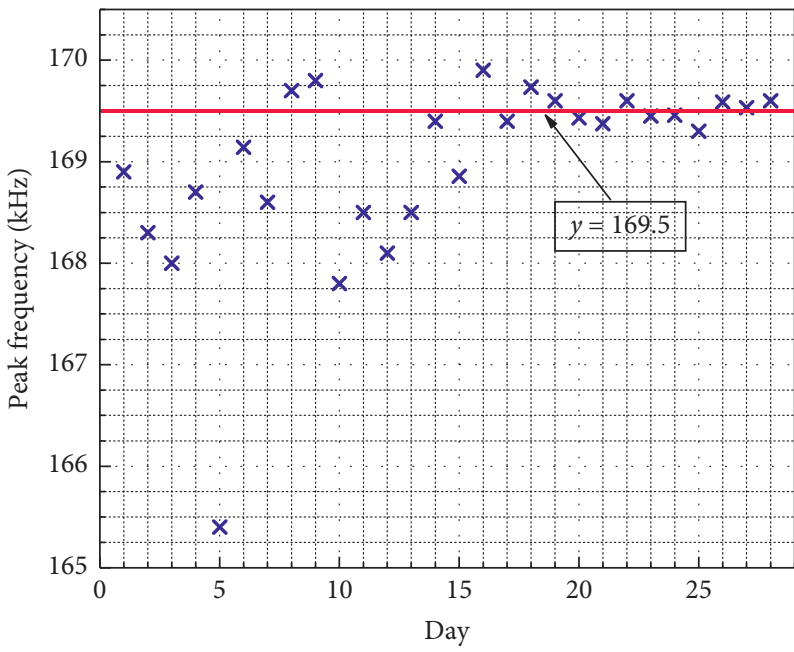

FIGURE 7: The frequency at the energy peak point.

which is more conducive to the propagation of stress waves in the concrete. Therefore, the signal amplitude is also increasing with the concrete age, which is consistent with the test results of [34] from Kong et al. And, in this experiment, the same SAs as in paper [34] were used. However, this conclusion is contrary to the results obtained by $\mathrm{Gu}$ et al. in [38] who used single frequency harmonics as the excitation signal. One mortar and three concrete cylinders instrumented with embedded piezoelectric transducers were tested by using the proposed method in [38]. And the experimental results show that the harmonic amplitude dropped with the strength development of the concrete specimens at early ages. This difference may be related to factors such as the signal source, concrete specimens, signal monitoring system, and the antinoise performance of SAs. Overall, all of these 

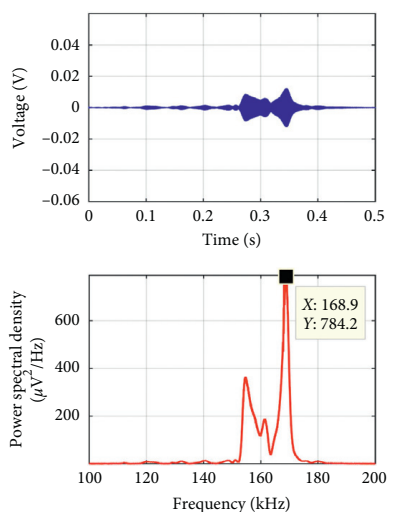

(a)
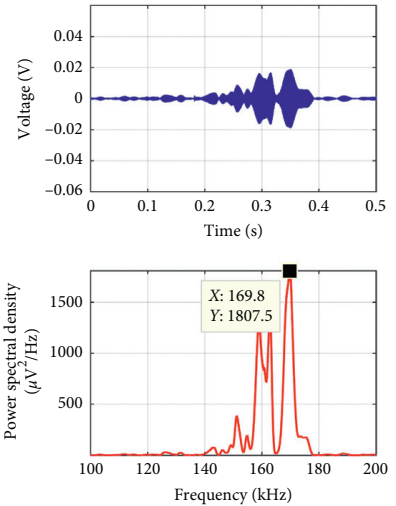

(e)
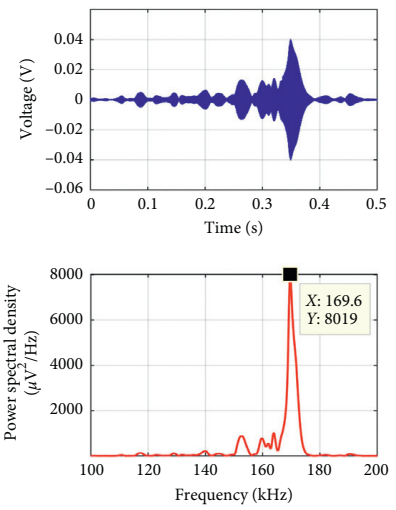

(i)
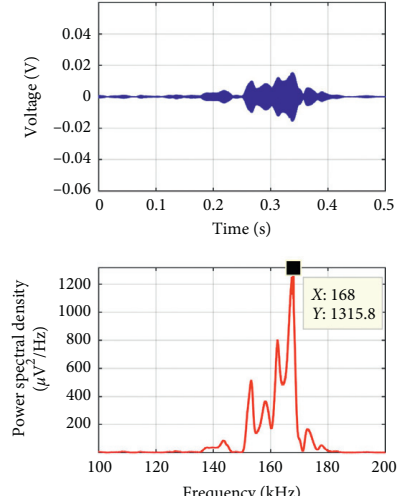

(b)
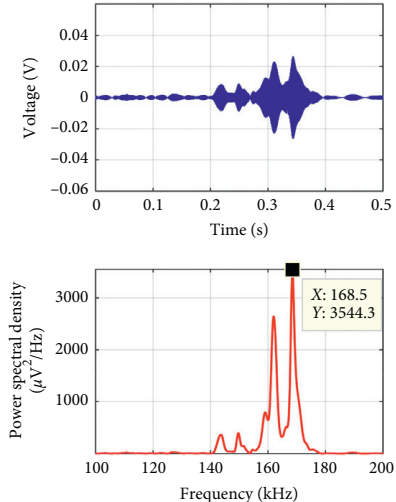

(f)
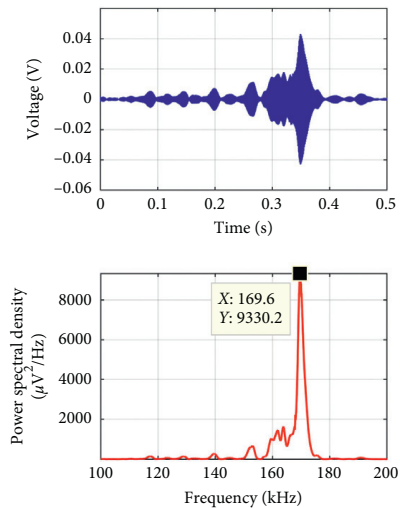

(j)
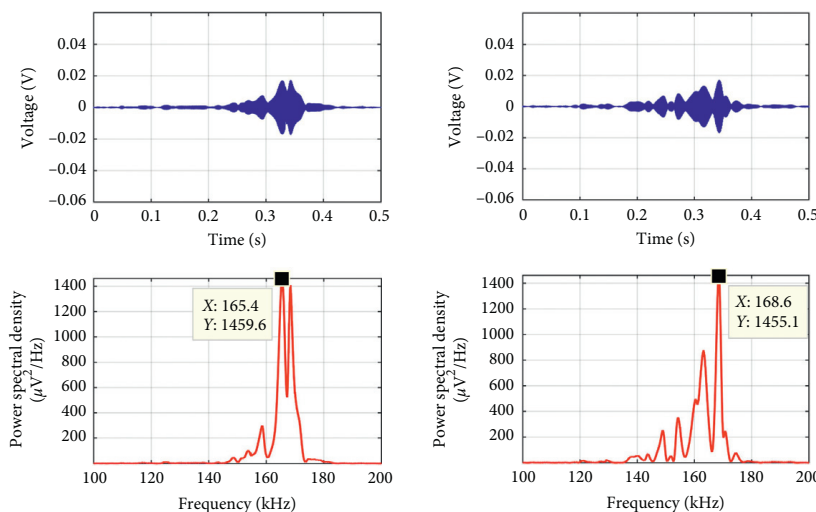

(c)
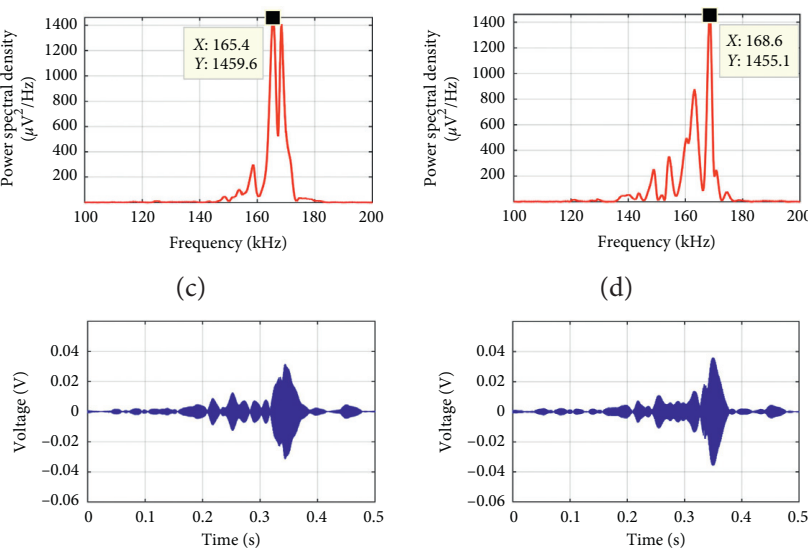

(d)
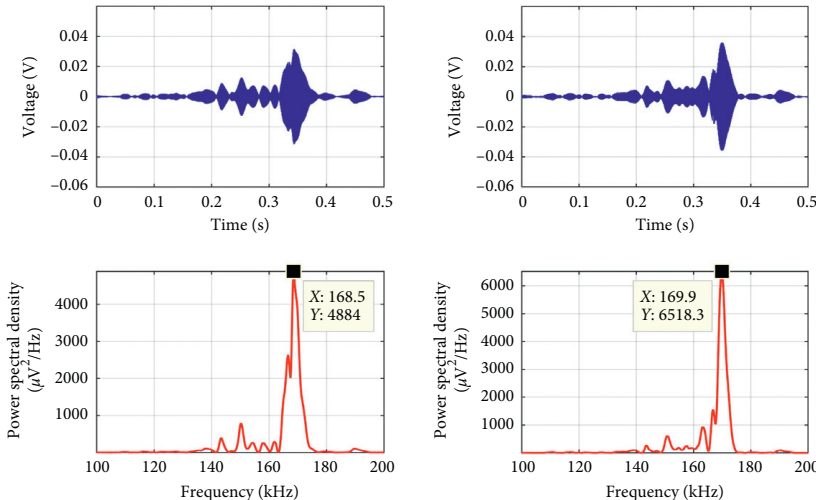

$(\mathrm{g})$
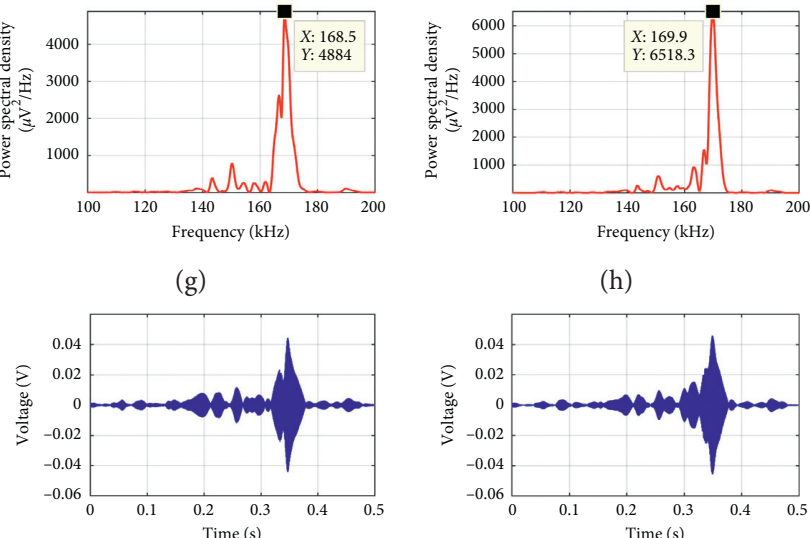

(h)
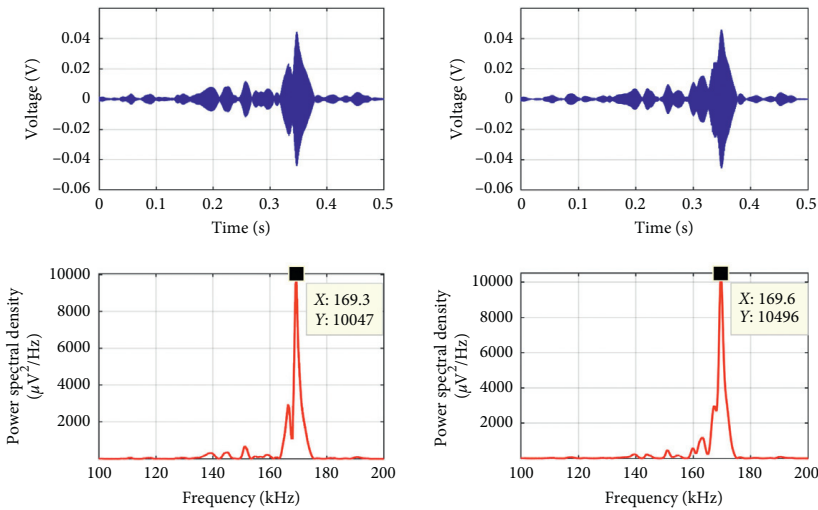

$(\mathrm{k})$

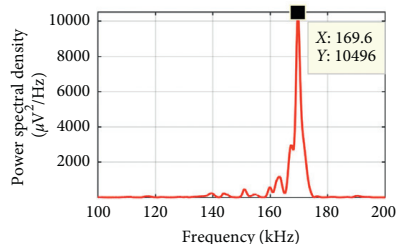

(l)

Figure 8: The power spectral density: (a) $1 \mathrm{~d}$, (b) $3 \mathrm{~d}$, (c) $5 \mathrm{~d}$, (d) $7 \mathrm{~d}$, (e) $9 \mathrm{~d}$, (f) $11 \mathrm{~d}$, (g) $13 \mathrm{~d}$, (h) $16 \mathrm{~d}$, (i) $19 \mathrm{~d}$, (j) $22 \mathrm{~d}$, (k) $25 \mathrm{~d}$, and (l) $28 \mathrm{~d}$.

test results show that as the concrete age strength increases, the signal amplitude changes in a certain pattern. In consequence, it can be preliminarily indicated that the detection method can effectively monitor the hydration process of concrete.

In order to understand the frequency components of the original signal, it is necessary to perform frequency domain analysis. The fast Fourier transform is performed on the original signal, and the obtained partial Short Time Fourier Transform (STFT) time-frequency diagram is as shown in Figure 6.
It can be seen from the STFT time-frequency diagram that, in the linear sweep range of $100 \mathrm{k} 200 \mathrm{k}$, the signal energy was concentrated in the local frequency band, which also indicated that the concrete has resonated in some local frequency bands. And it can be found that the frequency dispersion of concrete was more serious within 1 14 days. In the frequency range $140 \mathrm{kHz} \sim 180 \mathrm{kHz}$, there was energy accumulation. This indicated that the concrete in the GFRP tube was undergoing a stable hydration reaction during this period, and the strength increased rapidly. In addition, it can be seen from the STFT spectrogram that the natural 
frequency of the concrete began to stabilize slowly within 14 days to 28 days, and the frequency dispersion phenomenon began to decrease gradually, which indicated that the strength of the concrete was also beginning to stabilize.

The frequencies at the energy peak points in the respective STFT frequency domain graphs were extracted and plotted in Figure 7. As can be seen from Figure 7, the frequencies at the energy peak points were relatively scattered before the $14^{\text {th }}$ day, and most of them were substantially less than $169.5 \mathrm{kHz}$. After the $14^{\text {th }}$ day, the frequencies at the energy peak points of concrete were basically concentrated around $169.5 \mathrm{kHz}$, and this concentration effect was more and more stable. Through the above analysis, we can roughly determine the propagation frequency of the longitudinal wave in concrete used in this test was $169.5 \mathrm{kHz}$.

4.2. Power Spectral Density Analysis. The power spectral density analysis method was used to calculate and analyze the original signals of 28 days, and the respective power spectral density curves were obtained as shown in Figure 8. In order to clearly compare the changes in power spectral density, the power spectral density was extracted during the concrete early age when the propagation frequency of the longitudinal wave is $168.0 \mathrm{kHz}$, as shown in Figure 9. It can be seen from the figure that the early concrete strength development process can be roughly divided into three stages. In the first 4 days, the power spectrum density of the concrete is small, between $559.6 \mu \mathrm{V}^{2} / \mathrm{Hz}$ and $824.2 \mu \mathrm{V}^{2} / \mathrm{Hz}$, and the dispersion frequency band is wide. At this time, the hydration reaction in the concrete is ongoing, the concrete is not completely compacted, and the internal structure is not completely stable. When the stress wave passes through the concrete, a large amount of energy attenuation occurs in the unstable medium, and the energy distribution is also wide.

Within 5 to 14 days, the power spectral density increased with a very fast rate, reaching $2938.7 \mu \mathrm{V}^{2} / \mathrm{Hz}$ (about $90 \%$ of the maximum power spectral density). Moreover, the distribution of power spectral density has also begun to concentrate on $169.0 \mathrm{kHz} 170 \mathrm{kHz}$. From 15 days to 28 days, the internal structure of the concrete is basically stable, and the amplitude of the received stress wave changes very little. Both the time domain signal and the frequency domain signal exhibit only a distinct peak. The power spectral density is stable in the range of $3102.6 \mu \mathrm{V}^{2} / \mathrm{Hz} \sim 3213.1 \mu \mathrm{V}^{2} /$ $\mathrm{Hz}$ and is concentrated in the frequency range of $169.0 \mathrm{kHz} \sim 170.0 \mathrm{kHz}$. At the age of 28 days, the strength of the concrete is approximately $85 \%$ of the design strength.

4.3. Wavelet Packet Energy Analysis. By performing wavelet packet energy analysis on the signal collected by the sensor within 28 days, the wavelet packet energy variation of the signal during the concrete 28 days age can be obtained, as shown in Figure 10. It can be seen from the figure that, similar to the power spectral density curve, as the age increases, the energy change trend of the sensor monitoring signal can be divided into three stages.

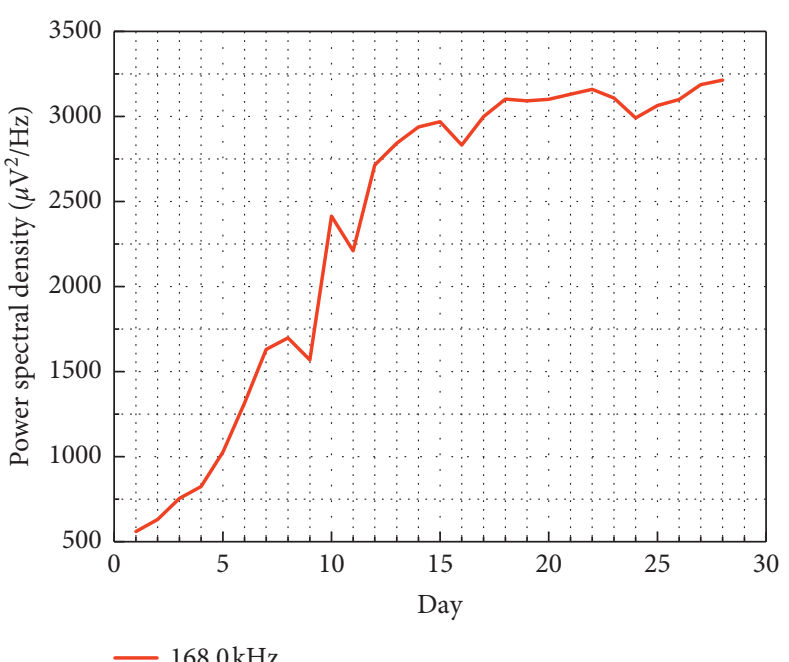

Figure 9: The power spectral density.

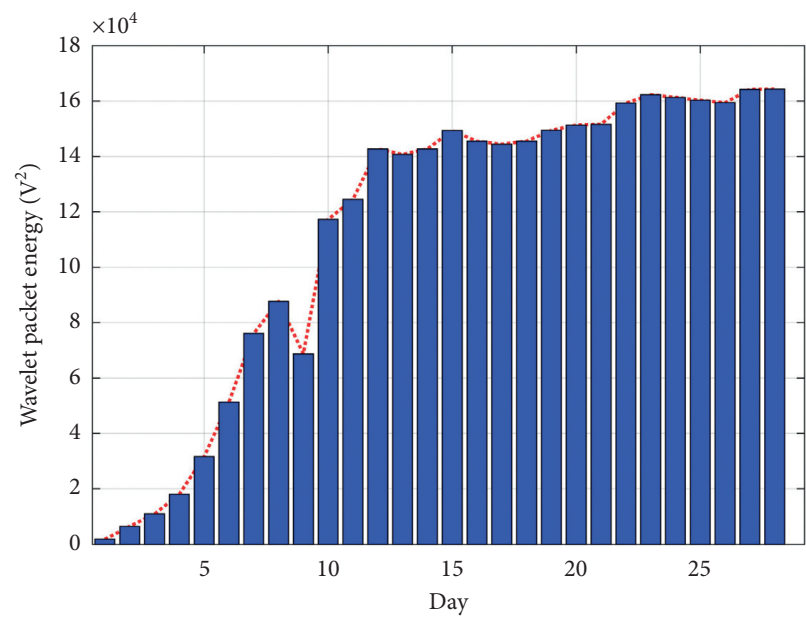

FIgURE 10: The result of wavelet packet energy.

The first stage is from day 1 to day 4 . The energy of the sensor monitoring signal reaches $1.845 \times 10^{4} \mathrm{~V}^{2}$ on the fifth day, reaching $11.28 \%$ of the maximum intensity of $16.355 \times 10^{4} \mathrm{~V}^{2}$ during the age. The second stage is from day 5 to day 14 , the sensor monitoring signal energy increases rapidly and finally reaches $14.292 \times 10^{4} \mathrm{~V}^{2}$, reaching $87.38 \%$ of the maximum intensity of $16.355 \times 10^{4} \mathrm{~V}^{2}$ during the concrete 28 days age. The third stage is from day 15 to day 28 , and the energy of the sensor monitoring signal fluctuates in a small range from $14.423 \times 10^{4} \mathrm{~V}^{2}$ to $16.355 \times 10^{4} \mathrm{~V}^{2}$.

\section{Conclusions}

In this paper, two piezoelectric SAs were embedded in the concrete-filled GFRP tube column specimen, and the changes of concrete strength in 28-day age were monitored and analyzed based on the piezoelectric active sensing method. The experimental results show that the frequency dispersion of concrete is more serious at the beginning. As 
the age increases, the propagation frequency of the longitudinal wave in concrete gradually stabilizes and eventually ends at around $169.5 \mathrm{kHz}$. By analyzing the power spectral density and wavelet packet of the signal between a pair of embedded SAs, three strength growth periods were clearly verified. The first stage is from 1 to 4 days, and the concrete strength increases slowly, only reaching about $11 \%$ of the maximum strength of the 28 days age. The second stage is from 5 to 14 days. At this stage, the power spectral density and wavelet packet energy change greatly, and the strength of the concrete increases rapidly. And on the $14^{\text {th }}$ day, the strength reached about $90 \%$ of the maximum strength of the age. The third stage is from 15 to 28 days, when the concrete strength is only slightly increased, and the change is minor. The wavelet packet energy and power spectral density of the signal also reach the maximum and are close to stability. Comparing and analyzing the received signal energy of the sensor and the power spectral density function of the stress wave of the concrete specimen, it can be found that the energy value and power spectral density value of the stress wave have the same trend with age strength in the three stages. Therefore, wavelet packet energy analysis and power spectral density analysis are feasible for strength monitoring of concrete age.

\section{Data Availability}

All data can be found in the manuscript.

\section{Conflicts of Interest}

The authors declare no conflicts of interest.

\section{Authors' Contributions}

W. Y. provided guidance and methodology; X. Y. and S. L. conceived and designed the experiments, analyzed the data, and wrote the paper; X. Y. and S. L. performed the experiments; and X. Y., S. L., and C. W. proofread and revised the paper. All authors have read and agreed to the published version of the manuscript.

\section{Acknowledgments}

This research was supported in part by Ningxia Natural Science Fund Project (2020AAC02007) and the National Natural Science Foundation of China (51608245).

\section{References}

[1] Y. Y. Lim, S. T. Smith, and C. K. Soh, "Wave propagation based monitoring of concrete curing using piezoelectric materials: review and path forward," NDT \& E International, vol. 99, pp. 50-63, 2018.

[2] N. Robeyst, C. De Schutter, C. Grosse, and N. De Belie, "Monitoring the effect of admixtures on early-age concrete behaviour by ultrasonic, calorimetric, strength and rheometer measurements," Magazine of Concrete Research, vol. 63, no. 10 , pp. 707-721, 2011.

[3] K. Ali-Benyahia, D. Sbartaï, S. Breysse, M. Kenai, and M. Ghrici, "Analysis of the single and combined non- destructive test approaches for on-site concrete strength assessment: general statements based on a real case-study," Case Studies in Construction Materials, vol. 6, pp. 109-119, 2017.

[4] E. Garcia, E. Erdogmus, M. Schuller, and D. Harvey, "Detecting onset of different types of flaws in reinforced concrete," ACI Materials Journal, vol. 116, no. 1, pp. 73-82, 2019.

[5] Y. Lu, Z. H. Ma, and Z. Li, "Ultrasonic monitoring of the early-age hydration of mineral admixtures incorporated concrete using cement-based piezoelectric composite sensors," Journal of Intelligent Material Systems and Structures, vol. 26, no. 3, pp. 280-291, 2015.

[6] C. Dumoulin, G. Karaiskos, J. Carette, S. Staquet, and A. Deraemaeker, "Monitoring of the ultrasonic P-wave velocity in early-age concrete with embedded piezoelectric transducers," Smart Materials \& Structures, vol. 21, no. 4, Article ID 047001, 2012.

[7] G. Song, Y. L. H. Gu, and H. DhondeHsu, "Concrete structural health monitoring using embedded piezoceramic transducers," Smart Materials and Structures, vol. 16, no. 4, pp. 959-968, 2007.

[8] H. Kim, X. Liu, E. Ahn, M. Shin, S. W. Shin, and S.-H. Sim, "Performance assessment method for crack repair in concrete using PZT-based electromechanical impedance technique," NDT \& E International, vol. 104, pp. 90-97, 2019.

[9] S. R. Sim, M. Barzegar, and M. Mohsenzadeh, "Damage detection of L-shaped beam structure with a crack by electromechanical impedance response: analytical approach and experimental validation," Journal of Nondestructive Evaluation, vol. 39, no. 2, 2020.

[10] S. Zhao, J. S. Fan, and J. Chen, "Quantitative assessment of the concrete gravity dam damage under earthquake excitation using electro-mechanical impedance measurements," Engineering Structures, vol. 191, pp. 162-178, 2019.

[11] D. Ai, H. Luo, C. Wang, and H. Zhu, "Monitoring of the loadinduced RC beam structural tension/compression stress and damage using piezoelectric transducers," Engineering Structures, vol. 154, pp. 38-51, 2018.

[12] S. W. Shin, A. R. Qureshi, and J. Y. Lee, "Piezoelectric sensor based nondestructive active monitoring of strength gain in concrete," Smart Materials and Structures, vol. 17, no. 5, Article ID 055002, 2008.

[13] S. W. Shin and T. K. Oh, "Application of electro-mechanical impedance sensing technique for online monitoring of strength development in concrete using smart PZT patches," Construction and Building Materials, vol. 23, no. 2, pp. 1185-1188, 2009.

[14] R. Tawie and H. K. Lee, "Monitoring the strength development in concrete by EMI sensing technique," Construction and Building Materials, vol. 24, no. 9, pp. 1746-1753, 2010.

[15] G. Park, H. H. Cudney, and D. J. Inman, "Impedance-based health monitoring of civil structural components," Journal of Infrastructure Systems, vol. 6, no. 4, pp. 153-160, 2000.

[16] D. W. Allen, D. M. Peairs, and D. J. Inman, "Damage detection by applying statistical methods to PZT impedance measurements," Smart Materials and Structures, vol. 5390, pp. 513-520, 2004.

[17] G. Park, K. Kabeya, H. H. Cudney, and D. J. Inman, "Impedance-based structural health monitoring for temperature varying applications," JSME International Journal Series A, vol. 42, no. 2, pp. 249-258, 1999.

[18] D. Wang and H. Zhu, "Damage identification in beam structures based on mechanical impedance characteristics," 
Progress in Safety Science and Technology, vol. IV, pp. 12771282, 2004.

[19] D.-S. Wang, Y. Liang-Ping, and H.-P. Zhu, "Strength monitoring of concrete based on embedded PZT transducer and the resonant frequency," in Proceedings of the 2010 Symposium on Piezoelectricity, Acoustic Waves and Device Applications (SPAWDA), pp. 202-205, Xiamen, China, December 2010.

[20] D. Wang and H. Zhu, "Monitoring of the strength gain of concrete using embedded PZT impedance transducer," Construction and Building Materials, vol. 25, no. 9, pp. 3703-3708, 2011.

[21] R. Howser, Y. Moslehy, H. Gu et al., "Smart-aggregate-based damage detection of fiber-reinforced-polymer-strengthened columns under reversed cyclic loading," Smart Materials and Structures, vol. 20, no. 7, Article ID 075014, 2011.

[22] M. Luo, W. Li, C. Hei, and G. Song, "Concrete infill monitoring in concrete-filled FRP tubes using a PZT-based ultrasonic time-of-flight method," Sensors, vol. 16, no. 12, p. 2083, 2016.

[23] X. Li, M. Luo, and C. Hei, "Quantitative evaluation of debond in concrete-filled steel tubular member (CFSTM) using piezoceramic transducers and ultrasonic head wave amplitude," Smart Materials and Structures, vol. 28, Article ID 075033, 2019.

[24] Q. Feng and J. Ou, "Self-sensing CFRP fabric for structural strengthening and damage detection of reinforced concrete structures," Sensors, vol. 18, no. 12, p. 4137, 2018.

[25] A. T. Martins, Z. Aboura, A. W. Harizi, K. Laksimi, and K. Hamdi, "Structural health monitoring by the piezoresistive response of tufted reinforcements in sandwich composite panels," Composite Structures, vol. 210, pp. 109-117, 2019.

[26] S. Bhalla and N. Kaur, "Prognosis of low-strain fatigue induced damage in reinforced concrete structures using embedded piezo-transducers," International Journal of Fatigue, vol. 113, pp. 98-112, 2018.

[27] H. Li and J. Ou, "The state of the art in structural health monitoring of cable-stayed bridges," Journal of Civil Structural Health Monitoring, vol. 6, no. 1, pp. 43-67, 2016.

[28] M. Mitra and S. Gopalakrishnan, "Guided wave based structural health monitoring: a review," Smart Materials and Structures, vol. 25, Article ID 053001, 2016.

[29] W. Li, S. C. M. Ho, M. Luo, Q. Huynh, and G. Song, "Fiber optic macro-bend based sensor for detection of metal loss," Smart Materials and Structures, vol. 26, Article ID 045002, 2017.

[30] Y. Bao, Y. Yu, H. Li et al., "Compressive sensing-based lost data recovery of fast-moving wireless sensing for structural health monitoring," Structural Control and Health Monitoring, vol. 22, no. 3, pp. 433-448, 2015.

[31] G. Song, H. Gu, Y. L. Mo, T. Hsu, H. Dhonde, and R. R. H. Zhu, "Health monitoring of a concrete structure using piezoceramic materials," in Proceedings of the Smart Structures and Materials 2005: Sensors and Smart Structures Technologies for Civil, Mechanical, and Aerospace Systems, pp. 108-119, San Diego, CA, USA, May 2005.

[32] G. Song, H. Gu, and Y. L. Mo, "Smart aggregates: multifunctional sensors for concrete structures-a tutorial and a review," Smart Materials \& Structures, vol. 17, no. 3, Article ID 033001, 2008.

[33] J. Zhu, S.-H. Tsai, and S. H. Kee, "Monitoring early age property of cement and concrete using piezoceramic bender elements," Smart Materials and Structures, vol. 20, no. 11, Article ID 115014, 2011.
[34] Q. Kong, S. Hou, and Q. Ji, "Very early age concrete hydration characterization monitoring using piezoceramic based smart aggregates," Smart Materials and Structures, vol. 22, no. 8, pp. 085025-08503, 2013.

[35] K. Chung, S. Kharkovsky, Q. Kong, and G. Song, "Cure-state monitoring of concrete and mortar specimens using smart aggregates," in Proceedings of the 2014 IEEE international instrumentation and measurement technology conference (I2MTC) proceedings, pp. 304-308, Montevideo, Uruguay, May 2014.

[36] J. Chen, P. Li, G. Song, and Z. Ren, "Piezo-based wireless sensor network for early-age concrete strength monitoring," Optik, vol. 127, no. 5, pp. 2983-2987, 2016.

[37] J. Cai, T. Wu, and Y. Chen, "Experimental study on monitoring the strength development of concrete based on piezoelectric impedance technology," Journal of Vibration and Shock, vol. 32, no. 2, pp. 124-128, 2013.

[38] H. Gu, H. G. Song, and S. Y. L. YanMo, "Concrete early-age strength monitoring using embedded piezoelectric transducers," Smart Materials and Structures, vol. 15, no. 6, pp. 1837-1845, 2006.

[39] K. Karimi, M. J. Tait, and W. W. El-Dakhakhni, "Testing and modeling of a novel FRP-encased steel-concrete composite column," Composite Structures, vol. 93, no. 5, pp. 1463-1473, 2011.

[40] T. Yu, J. G. Teng, Y. L. Wong, and S. L. Dong, "Stress-strain behavior of concrete in hybrid FRP-concrete-steel doubleskin tubular columns," Journal of Structural Engineering, vol. 136, no. 4, pp. 379-389, 2010.

[41] B. Xue and J. Gong, "Study on steel reinforced concrete-filled GFRP tubular column under compression," Thin-Walled Structures, vol. 106, pp. 1-8, 2016.

[42] W. Yang, S. Li, and Y. Xia, "Experimental study on axial compression of steel-encased concrete filled GFRP tubular short column," Journal of Shenyang Jianzhu University (Natural Science), vol. 36, no. 2, pp. 229-238, 2020.

[43] W. Yang, X. Yang, and S. Li, "Monitoring of interfacial debonding of concrete filled pultrusion-GFRP tubular column based on piezoelectric smart aggregate and wavelet analysis," Sensors, vol. 20, no. 7, p. 2149, 2020.

[44] W. Yang, Q. Kong, S. C. M. Ho, Y.-L. Mo, and G. Song, "Realtime monitoring of soil compaction using piezoceramic-based embeddable transducers and wavelet packet analysis," IEEE Access, vol. 6, pp. 5208-5214, 2018.

[45] B. Han, Y. Wang, S. Dong et al., "Smart concretes and structures: a review," Journal of Intelligent Material Systems and Structures, vol. 26, no. 11, pp. 1303-1345, 2015.

[46] N. Kaur, S. C. S. Bhalla, and S. C. G. Maddu, "Damage and retrofitting monitoring in reinforced concrete structures along with long-term strength and fatigue monitoring using embedded Lead Zirconate Titanate patches," Journal of Intelligent Material Systems and Structures, vol. 30, no. 1, pp. 100-115, 2019.

[47] K. Xu and Y. Li, "The power spectrum estimation method based on continuous wavelet transformation," Journal of Applied Sciences, vol. 2, no. 21, pp. 157-160, 2003.

[48] B. Xu, B. Li, and G. Song, "Active interfacial performance monitoring for concrete filled steel tube with embedded PZT techniques using power spectral density analysis," in Proceedings of the Earth and Space 2012: Engineering, Science, Construction, and Operations in Challenging Environments, pp. 1371-1379, Pasadena, CA, USA, April 2012.

[49] B. Das, S. Pal, and S. Bag, "Weld defect identification in friction stir welding using power spectral density," in 
Proceedings of the IOP Conference Series: Materials Science and Engineering, Article ID 012049, Dubai, United Arab Emirates, April 2018.

[50] Z. D. Zheng, Z. R. Lu, W. H. Chen, and J. K. Liu, "Structural damage identification based on power spectral density sensitivity analysis of dynamic responses," Computers \& Structures, vol. 146, pp. 176-184, 2015.

[51] B. Zhao, J. D. Lei, and W. L. XuYang, "Experimental study on micro-damage identification in reinforced concrete beam with wavelet packet and DIC method," Construction and Building Materials, vol. 210, pp. 338-346, 2019.

[52] J.-G. Han, W.-X. Ren, and Z.-S. Sun, "Wavelet packet based damage identification of beam structures," International Journal of Solids and Structures, vol. 42, no. 26, pp. 6610-6627, 2005.

[53] G. Facchini, L. Bernardini, S. Atek, and P. Gaudenzi, "Use of the wavelet packet transform for pattern recognition in a structural health monitoring application," Journal of Intelligent Material Systems and Structures, vol. 26, no. 12, pp. 1513-1529, 2015.

[54] J. Zhang, Y. Li, Y. Huang, J. Jiang, and S.-C. Ho, “A feasibility study on timber moisture monitoring using piezoceramic transducer-enabled active sensing," Sensors, vol. 18, no. 9, p. 3100, 2018.

[55] Y. Ding and A. Li, "Structural health monitoring of long-span suspension bridges using wavelet packet analysis," Earthquake Engineering and Engineering Vibration, vol. 6, no. 3, pp. 289-294, 2007.

[56] E. V. Glushkov, N. V. Glushkova, O. V. Kvasha, and R. Lammering, "Selective Lamb mode excitation by piezoelectric coaxial ring actuators," Smart Materials \& Structures, vol. 19, no. 3, Article ID 035018, 2010. 